\title{
Afectaciones a la salud tras la migración y el papel mediador de la aculturación y la cohesión familiar
}

\author{
Health effects after migration and the mediating role of acculturation and family cohesion
}

Raúl Alberto Zavaleta-Abad' orcid.org/0000-0003-0475-3109

Yolanda Campos-Uscanga ${ }^{*}$ orcid.org/0000-0002-51 14-3621

Instituto de Salud Pública, Universidad Veracruzana. Veracruz, México

\section{Resumen}

Introducción: La migración es un proceso que implica cambios para el migrante, estos se ven reflejados en las actividades y prácticas que se realizan en el lugar receptor, y muchas veces no son las mismas de la cultura de procedencia, sin embargo las va adquiriendo de forma paulatina y gradual, hasta ser partícipe de ellas, alterando su cohesión familiar y propiciando el proceso de aculturación. Dichos cambios pueden tener efectos en la salud del migrante. Objetivo: Identificar los efectos que tiene la migración en la salud del migrante y su papel mediador de la cohesión familiar y la aculturación. Materiales y métodos: Se realizó una búsqueda sistemática (metodología PRISMA) en la base de datos PubMed de artículos completos, utilizando como palabras clave: migrante, aculturación, cohesión familiar. Resultados: La elevada cohesión familiar es un factor protector de la salud, porque fortalece la identidad y pertenencia cultural del inmigrante, mientras que la aculturación trae consigo ciertas conductas desfavorables para la salud, relacionadas con la necesidad de ser aceptado y de participar en las actividades y prácticas del lugar receptor. Conclusiones: El fortalecimiento de la cohesión familiar puede ser una estrategia para mejorar la condición de salud de las personas que migran.

Palabras clave: Salud; migración; aculturación; cohesión familiar. (Fuente: DeCS, Bireme).

\begin{abstract}
Introduction: Migration is a process that implies changes for the migrant, these are reflected in the activities and practices that are carried out in the receiving place, and often they are different from the place of origin. However these activities are acquired gradually, and by participating in them, they alter family cohesion and promote the acculturation process. Such changes may have an effect on the health of the migrant. Objective: To identify the effects that migration has on the health of the migrant and the mediating role of family cohesion and acculturation. Materials and methods: A systematic search (PRISMA methodology) was carried out in the PubMed database of complete articles, using as keywords: Migrant, acculturation, family cohesion. Results: High family cohesion is a protective health factor, because it strengthens the identity and cultural belonging of the immigrant. Acculturation brings certain unfavorable behaviors for health, related to the need to be accepted and to participate in activities and practices of the receiving place. Conclusions: Strengthening family cohesion can be a strategy to improve the health condition of people who migrate.
\end{abstract}

Key words: Health; migration; acculturation; family cohesion. (Source: DeCS, Bireme).

\footnotetext{
*Autor de correspondencia

Yolanda Campos Uscanga

e-mail: ycampos@uv.mx
} 


\section{Introducción}

La migración es un fenómeno común en el mundo

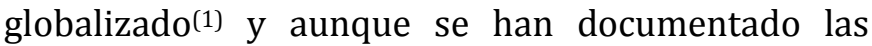
causas por las cuales el migrante deja su lugar de origen, actualmente se desconocen los efectos que puede traer consigo la migración en las diferentes esferas de su vida. Por lo tanto, es importante conocer, como cambian algunos de comportamientos relacionados con la salud, la cultura y la identidad.

La identidad cultural es un constructo social, donde se aprenden $y$ ponen en práctica costumbres, tradiciones y valores de la cultura y la familia a la que se pertenece, dando lugar a diferencias entre los individuos que provienen de distintas culturas(2). Sin embargo, no se puede hablar de culturas aisladas, ya que, gracias a la migración, la transnacionalización (mercados extranjeros en lugares diferentes a los de su origen), las guerras y las alianzas entre diferentes culturas, se han diluido las fronteras entre los países, culturas y sociedades. Esto lleva a que con frecuencia dos o varias culturas interactúen entre sí, generando interculturalidad (participación de dos o más culturas diferentes en un mismo lugar, espacio o tiempo, ambas culturas practican su valores costumbres y tradiciones sin afectar o participar en la otra)(3).

Por otro lado, esta interculturalidad también puede dar lugar a la hibridación cultural, entendida como la reorganización cultural que tienen dos o más grupos sociales (diferentes culturas) para formar una nueva; implica procesos socioculturales en los que algunas estructuras o prácticas discretas que existían de forma separada, se combinen para generar nuevas estructuras, objetos y prácticas, que se ven reflejadas en las costumbres, tradiciones y valores ${ }^{(4)}$.

Lo anterior permite suponer que durante el proceso de migración los individuos experimentan cambios a nivel individual, familiar y social, los cuales son visibles de forma inmediata por el cambio de residencia, de espacios, de personas con quienes convive o de ocupación, pero más allá de estos cambios a corto plazo pudiera estar sucediendo un proceso gradual de pérdida de identidad cultural que influya en su desarrollo personal y familiar(5).

\section{Cohesión familiar}

La familia es considerada el principal agente de socialización en el que se produce el aprendizaje cuando los miembros de la familia interactúan entre si(6). Esta interacción determina el comportamiento afectivo de sus integrantes ${ }^{(7,8)}$ y el apego familiar que tienen entre sí( $(9,10)$, de tal manera que la cohesión familiar es una expresión de apoyo, cuidado, pertenencia y aceptación dentro de la familia(5). En algunas culturas es común encontrar alta cohesión familiar, particularmente marcada por relaciones estrechas con los miembros de la familia nuclear, lealtad, reciprocidad y solidaridad(11). Es indudable que las familias migrantes se enfrentan a una situación especial, ya que los valores, las costumbres y las tradiciones que tienen de su cultura pueden diferir de las presentes en el lugar receptor(12). Esta diferencia cultural puede influir en los efectos positivos o negativos en las distintas esferas de la vida del migrante y estar mediada por la cohesión familiar(5,13).

\section{Migración y aculturación}

Cuando el migrante llega al lugar receptor se ve abocado a la actualización, que se define como la pérdida de valores costumbres y tradiciones de la cultura a la que se pertenece(14), en algunos casos incluye el cambio del uso de la lengua nativa, creencias y prácticas que el migrante realiza(15). Es considerado como un proceso continuo que ocurre a medida que los grupos de migrantes adquieren una creciente exposición a las creencias, rasgos, identificaciones y estilos de vida de la cultura dominante(16) que puede o no generar estrés al migrante, en algunos casos incluso facilita el desarrollo en diferentes ámbitos de la vida(17).

Desde la década de los 80's se ha puesto en manifiesto un enfoque psicológico que trata de explicar cómo sucede el proceso de aculturación a través de un enfoque bidimensional en el que el individuo puede moverse en ambos sentidos(18), la primera dimensión implica el mantenimiento o la pérdida de la propia cultura y la segunda, la participación o adopción de los aspectos sociales, culturales y políticos de la cultura receptora ${ }^{(1)}$.

Se ha visto que el mantenimiento y la participación dentro de las dos culturas (la propia y la receptora) conduce a cuatro orientaciones individuales diferentes de aculturación; a. integración: acepta ser partícipe de la cultura receptora, intentando mantener los valores y costumbres de su cultura; $b$. asimilación: no mantiene su identidad cultural y adopta completamente las actitudes y comportamientos de la nueva cultura(19); c. 
separación: busca valorar y pertenecer a su propia cultura, debido a que rechaza la cultura receptora; y d. marginación tiene poco interés en el mantenimiento de valores costumbres y tradiciones de la cultura original, pero no se identifica con las características de la cultura receptora(18).

Durante el proceso de aculturación existe un cambio conductual y actitudinal(20), por lo general los migrantes traen consigo rasgos e ideologías de su cultura de origen(14) que pueden ejercer un efecto protector en diferentes aspectos de su vida(21), pero a medida que se van aculturando pueden producir efectos negativos para la misma. Por tal motivo, se realizó una búsqueda sistemática para identificar los efectos que tiene la migración en la salud del migrante y el papel mediador que puede desempeñar la cohesión familiar y la aculturación.

\section{Materiales y métodos}

\begin{abstract}
Protocolo y fuentes de información
Esta revisión se realizó de acuerdo con la propuesta para mejorar las revisiones sistemáticas $y$ metaanálisis (PRISMA)(21), que proporciona una guía clara, práctica y sistemática en este tipo de investigación.
\end{abstract}

\section{Estrategia de búsqueda y proceso de selección de estudios}

Se realizó una búsqueda exhaustiva en la base de datos de PubMed durante noviembre de 2017 hasta febrero de 2018. Los términos de búsqueda se basaron en las palabras clave MeSH para "migrante", "aculturación" y "cohesión familiar". La estrategia de búsqueda se define en la Tabla 1.

Tabla 1. Estrategia de búsqueda de información

\begin{tabular}{|c|c|}
\hline Base de datos & Búsqueda académica completa (PubMed) con textos completos. \\
\hline Palabras clave & $\begin{array}{l}\text { Palabras clave MeSH: Aculturación, migrante y cohesión familiar. Además se utilizaron las siguientes } \\
\text { combinaciones: migrante y aculturación o cohesión familiar y aculturación o migrante y cohesión } \\
\text { familiar }\end{array}$ \\
\hline Criterios de selección & $\begin{array}{l}\text { 1. El estudio fue publicado en una revista científica perteneciente a la base de datos de PubMed } \\
\text { 2. El estudio fue publicado en idioma español o inglés } \\
\text { 3. El estudio investigó } 1 \text { ó } 2 \text { variables en común (migrante y aculturación o cohesión familiar y } \\
\text { aculturación o migrante y cohesión familiar) } \\
\text { 4. El estudio podía ser longitudinal o transversal, siempre y cuando estuvieran } 1 \text { ó } 2 \text { variables de } \\
\text { interés } \\
\text { 5. La población estudiada está compuesta por migrantes y / o refugiados sin importar el sexo, país o } \\
\text { región de procedencia, nivel socioeconómico, nivel educativo } \\
\text { 6. Las poblaciones estudiadas eran adolescentes y adultos principalmente } \\
\text { 7. El documento fue publicado entre los años } 2000 \text { y } 2017\end{array}$ \\
\hline
\end{tabular}

\section{Validación y evaluación de calidad}

Los artículos obtenidos en la búsqueda fueron evaluados en términos de calidad, afinidad y congruencia con el tema de interés, en tres rondas. En la primera ronda, los artículos se incluyeron o excluyeron en función de su título (afinidad con el tema de interés). En la segunda ronda, los artículos fueron retenidos o excluidos después de revisar sus resúmenes (congruencia). En la tercera ronda, se obtuvo la versión de texto completo de cada uno de los artículos restantes (congruencia entre sus objetivos, pregunta de investigación y resultados). Finalmente, sólo se tomaron en cuenta aquellos artículos que cumplieron los 3 filtros y los criterios de selección.
Se identificaron 2.019 documentos en la búsqueda inicial. La mayoría de estos fueron rechazados por no cumplir criterios de selección (1.962) o por no cumplir con los términos de afinidad (1.919), calidad (1.893) y congruencia (1.873). Solo 17 documentos cumplieron con lo establecido.

\section{Resultados}

Existe controversia con respecto a las contribuciones de la cohesión familiar a diversas esferas de la vida de los migrantes. De forma general se encontró que mayor cohesión familiar se relaciona con menor consumo de alcohol, tabaco, marihuana y otras drogas y con mayor la realización de actividad física (Tabla 2). 
Tabla 2. Impacto de la cohesión familiar en la salud de los migrantes

\begin{tabular}{|c|c|c|}
\hline Objetivo del estudio & Participantes & Metodología \\
\hline $\begin{array}{l}\text { Examinar cómo las diferentes } \\
\text { dimensiones familiares se } \\
\text { asociaron con el } \\
\text { comportamiento de fumar en } \\
\text { hombres asiático-americanos } \\
\text { y si las asociaciones variaban } \\
\text { según el grupo étnico(22). }\end{array}$ & $\begin{array}{lr}\text { Adultos } & \text { asiáticos } \\
\text { americanos que } \\
\text { participaron en la Encuesta } \\
\text { Nacional Latinoamericana } \\
\text { y Asiática de 2002 a } \\
2003(22) \text {. }\end{array}$ & $\begin{array}{l}\text { Estudio transversal con } 998 \\
\text { adultos asiáticos americanos } \\
\text { donde divididos en } 4 \text { subgrupos } \\
\text { étnicos (chino, vietnamita, } \\
\text { filipino y otro), se realizaron } \\
\text { regresiones logísticas } \\
\text { multivariadas ponderadas. Se } \\
\text { crearon algunas preguntas } \\
\text { relacionadas con las dimensiones } \\
\text { de la escala de capital social y se } \\
\text { compararon para medir su } \\
\text { fiabilidad. }\end{array}$ \\
\hline
\end{tabular}

\begin{tabular}{|c|c|c|}
\hline $\begin{array}{l}\text { Probar un modelo } \\
\text { culturalmente relevante para }\end{array}$ & $\begin{array}{llr}\text { Adolescentes } & \text { y sus } \\
\text { cuidadores } & \text { hispanos }\end{array}$ & $\begin{array}{l}\text { Estudio de cohorte, utilizando un } \\
\text { modelo bidimensional y }\end{array}$ \\
\hline examinar posibles & migrantes, reclutados en 23 & multidominio de aculturación. Se \\
\hline determinantes & escuelas de Los Ángeles y & aplicó la e \\
\hline comportamientos de riesgo & Miami seleccionadas al & corta de participación bicultural \\
\hline $\begin{array}{lr}\text { para la } & \text { salud } \quad \text { y } \\
\text { sintomatología } & \text { depresiva }\end{array}$ & $\operatorname{azar}(23)$ & $\begin{array}{l}\text { (BIQ-S) y la cohesión familiar a } \\
302 \text { participantes. Se midió con la }\end{array}$ \\
\hline $\begin{array}{l}\text { entre los hispanos en la } \\
\text { adolescencia media(23). }\end{array}$ & & $\begin{array}{l}\text { subescala de seis ítems de la } \\
\text { Escala de Relaciones Familiares. }\end{array}$ \\
\hline
\end{tabular}

Mayor cohesión familiar percibida por los adolescentes se asoció con menor consumo de tabaco y alcohol y menos síntomas depresivos en adolescentes. Mientras que mayor cohesión familiar percibida por los cuidadores, se asoció con mayor tabaquismo, uso inconsciente del condón y síntomas depresivos en los adolescentes. Esta contradicción pone en evidencia que la percepción de los adolescentes es mejor predictor del funcionamiento familiar por cuanto las intervenciones deben partir desde ellos(23).

\begin{abstract}
Identificar los factores a nivel familiar, como la cohesión y el conflicto familiar, asociados con la actividad física adecuada durante la adolescencia tardía entre los participantes que informaron actividad física inadecuada durante la adolescencia temprana(24).
\end{abstract}

Adolescentes mexicanos de 13 a 16 años de edad que viven en Estados Unidos(24).
Estudio de cohorte prospectivo inicia en 2005-06 (6 años), los datos analizados corresponden a los seguimientos 1 y 2 (2008-09 2010-11). Se aplicaron cuestionarios relacionados con la actividad física, además, una escala de aculturación lingüística y la escala Family Life Questionnaire para evaluar cohesión familiar a 711 adolescentes.

\begin{tabular}{|c|c|c|c|}
\hline $\begin{array}{l}\text { "Evaluar las diferencias } \\
\text { culturales, étnicas y de } \\
\text { género en el consumo de } \\
\text { alcohol y los problemas } \\
\text { relacionados con el alcohol } \\
\text { entre los estudiantes } \\
\text { hispanos"(25). }\end{array}$ & 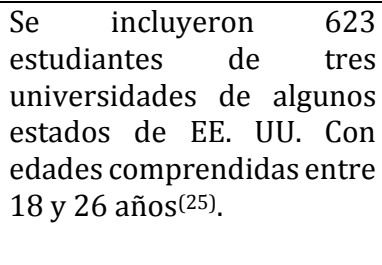 & $\begin{array}{l}\text { Estudio } \\
\text { aleatorizado. Los participantes } \\
\text { contestaron la encuesta en línea, } \\
\text { se utilizó la escala de } \text { Attitudinal } \\
\text { Familism Scale. }\end{array}$ & $\begin{array}{l}\text { Los resultados sugirieron que la } \\
\text { cohesión familiar protege del } \\
\text { consumo de alcohol en estudiantes } \\
\text { universitarios(25). }\end{array}$ \\
\hline
\end{tabular}

Se observaron mayores niveles de cohesión familiar en aquellos que realizan mayor actividad física moderada-vigorosa. La cohesión familiar y el estatus social subjetivo favorecen la actividad física moderada intensa en los adolescentes(24).
En algunos grupos étnicos se ha encontrado que el proceso de aculturación causa estrés, llevando a la adquisición de comportamientos nocivos en diferentes esferas de la vida del migrante (Tabla 3). 
Tabla 3. Aculturación en migrantes y su impacto en la salud

\begin{tabular}{|c|c|c|c|}
\hline Objetivo del estudio & Participantes & Metodología & Resultados \\
\hline $\begin{array}{l}\text { Examinar la asociación entre } \\
\text { la aculturación y la actividad } \\
\text { física en la primera } \\
\text { generación de migrantes } \\
\text { latinas que viven en Carolina } \\
\text { del Norte(27). }\end{array}$ & $\begin{array}{l}\text { Migrantes latinas que viven } \\
\text { en Carolina del Norte, de } 20 \\
\text { a } 50 \text { años de edad(27). }\end{array}$ & $\begin{array}{l}\text { Estudio transversal con } 671 \\
\text { migrantes latinas, se utilizó la } \\
\text { escala corta de aculturación para } \\
\text { hispanos (SASH). }\end{array}$ & $\begin{array}{l}\text { Aquellas con mayor aculturación en } \\
\text { el idioma inglés tenían más } \\
\text { probabilidades de tener menor nivel } \\
\text { educativo, ser empleadas, no tener } \\
\text { compañeras de juego, tener menos } \\
\text { hijos y calificar su salud como } \\
\text { excelente o muy buena(27). }\end{array}$ \\
\hline $\begin{array}{l}\text { Examinar la asociación entre } \\
\text { la aculturación y la obesidad } \\
\text { en adultos hispanos/latinos } \\
\text { que viven en los Estados } \\
\text { Unidos(28). }\end{array}$ & $\begin{array}{l}\text { Latinos de } 18 \text { a } 74 \text { años de } \\
\text { edad, de } 4 \text { áreas urbanas de } \\
\text { Estados Unidos que } \\
\text { participaron en The } \\
\text { Hispanic Community Health } \\
\text { Study /Study of Latinos(28). }\end{array}$ & $\begin{array}{l}\text { Estudio de cohorte con } 16.415 \\
\text { participantes a quienes se aplicó } \\
\text { la escala corta de aculturación } \\
\text { para hispanos (SASH). }\end{array}$ & $\begin{array}{l}\text { La exposición prolongada a los } \\
\text { ambientes obesogénicos en } \\
\text { conjunto con la aculturación, son } \\
\text { importantes factores de riesgo para } \\
\text { la obesidad(28). }\end{array}$ \\
\hline $\begin{array}{l}\text { Examinar la asociación de la } \\
\text { aculturación con diversos } \\
\text { factores de riesgo } \\
\text { cardiovascular entre los } \\
\text { latinos con diabetes en el sur } \\
\text { de la Florida(29). }\end{array}$ & $\begin{array}{l}\text { Latinos con diabetes mal } \\
\text { controlada(29). }\end{array}$ & $\begin{array}{l}\text { Estudio transversal con } 300 \\
\text { participantes con diabetes, a } \\
\text { quienes se aplicó la escala corta } \\
\text { de aculturación para hispanos } \\
\text { (SASH). }\end{array}$ & $\begin{array}{l}\text { La aculturación se asoció con el } \\
\text { tabaquismo y este a su vez con el } \\
\text { riesgo cardiovascular. Sin embargo, } \\
\text { no hubo asociación entre mayor } \\
\text { aculturación y mayor riesgo } \\
\text { cardiovascular en los latinos con } \\
\text { diabetes(29). }\end{array}$ \\
\hline $\begin{array}{l}\text { Describir el uso del cigarrillo } \\
\text { entre los adultos } \\
\text { hispanos/latinos a través del } \\
\text { grado de aculturación a la } \\
\text { cultura dominante de los } \\
\text { Estados Unidos(30). }\end{array}$ & $\begin{array}{l}\text { Latinos que participaron en } \\
\text { el estudio de salud } \\
\text { comunitaria(30). }\end{array}$ & $\begin{array}{l}\text { Estudio transversal con } 16.322 \\
\text { latinos de } 18 \text { a } 74 \text { años de edad, } \\
\text { donde se utilizó la escala corta de } \\
\text { aculturación para hispanos } \\
\text { (SASH). }\end{array}$ & $\begin{array}{l}\text { Mayor aculturación se asoció con } \\
\text { mayor probabilidad de ser } \\
\text { fumadores, estas asociaciones } \\
\text { fueron más fuertes y más } \\
\text { consistentes entre las mujeres. } \\
\text { Estas conductas no son propias de la } \\
\text { cultura a la que pertenecen las } \\
\text { mujeres del estudio(30). }\end{array}$ \\
\hline $\begin{array}{l}\text { Evaluar la relación de la } \\
\text { aculturación con la actividad } \\
\text { física y las conductas } \\
\text { sedentarias entre las mujeres } \\
\text { hispanas en California(21). }\end{array}$ & $\begin{array}{lrr}\text { Mujeres de } & \geq 18 \text { años } \text { en } \\
\text { California } & \text { que } & \text { se } \\
\text { identificaron } & & \text { como } \\
\text { hispanas(21). } & & \end{array}$ & $\begin{array}{l}\text { Estudio telefónico aleatorio } \\
\text { transversal. La aculturación se } \\
\text { midió mediante un cuestionario } \\
\text { diseñado expresamente para la } \\
\text { investigación. }\end{array}$ & $\begin{array}{l}\text { La aculturación puede implicar la } \\
\text { adopción de una serie de } \\
\text { comportamientos poco saludables } \\
\text { de la sociedad de acogida, como un } \\
\text { aumento del tiempo dedicado a ver } \\
\text { televisión, lo que a su vez se asocia } \\
\text { con comportamientos } \\
\text { sedentarios(21). }\end{array}$ \\
\hline $\begin{array}{l}\text { Describir la prevalencia de } \\
\text { los principales factores de } \\
\text { riesgo de enfermedad } \\
\text { cardiovascular y enfermedad } \\
\text { coronaria } \\
\text { hispanos/latinos } \\
\text { estadounidenses } \\
\text { diferentes } \\
\text { examinando las relaciones } \\
\text { entre estado socioeconómico } \\
\text { y aculturación(31). }\end{array}$ & $\begin{array}{l}\text { Migrantes latinos/ } \\
\text { hispanos que viven en } \\
\text { Estados Unidos, con edades } \\
\text { de } 18 \text { a } 74 \text { años(31). }\end{array}$ & $\begin{array}{l}\text { Estudio de cohorte multicéntrico } \\
\text { prospectivo } 15.079 \text { participantes, } \\
\text { donde se utilizó la escala corta de } \\
\text { aculturación para hispanos } \\
\text { (SASH). }\end{array}$ & $\begin{array}{l}\text { Los participantes con menores } \\
\text { ingresos o bajo nivel de educación } \\
\text { estaban más aculturados y tenían } \\
\text { tasas más altas de tabaquismo, } \\
\text { diabetes, obesidad } \\
\text { hipercolesterolemia, además, tenían } \\
\text { una prevalencia mayor de } 3 \text { o más } \\
\text { factores de riesgo cardiovascular(31). }\end{array}$ \\
\hline
\end{tabular}

Al parecer la cohesión familiar favorece ciertas conductas saludables en el migrante. La aculturación por su parte promueve factores de riesgo para la salud del mismo. Algunas investigaciones han estudiado estás variables en conjunto encontrando relaciones directas entre aculturación y cohesión familiar (Tabla 4). 
Tabla 4. Cohesión familiar, aculturación y efectos en la salud del migrante

\begin{tabular}{|c|c|c|c|}
\hline Nombre del estudio & Participantes & Metodología & Resultados \\
\hline $\begin{array}{l}\text { Explorar los factores } \\
\text { psicosociales y los factores } \\
\text { de cohesión familiar, apoyo } \\
\text { social, participación } \\
\text { religiosa, identidad racial y } \\
\text { étnica y como se relaciona } \\
\text { con el trastorno depresivo } \\
\text { mayor, el trastorno de } \\
\text { ansiedad general y la } \\
\text { ideación suicida entre } \\
\text { latinas (32). }\end{array}$ & $\begin{array}{l}\text { Mujeres latinas } \\
\text { mayores de } 18 \text { años, } \\
\text { que participaron en la } \\
\text { Primera encuesta } \\
\text { epidemiológica } \\
\text { nacional de salud } \\
\text { mental de las latinas } \\
\text { residentes en los } \\
\text { Estados Unidos(32). }\end{array}$ & $\begin{array}{l}\text { Estudio transversal que empleó } \\
\text { algunos cuestionarios de la } \\
\text { National Latino and Asian } \\
\text { American Study (NLAAS), que } \\
\text { incluyen preguntas sobre } \\
\text { cohesión familiar y aculturación. } \\
\text { La muestra fue de } 1.427 \text { latinas. }\end{array}$ & $\begin{array}{l}\text { Existe mejor cohesión familiar conforme } \\
\text { aumenta la edad, hay identidad étnica y } \\
\text { mayor participacion religiosa, pero } \\
\text { disminuye cuando se nace en Estados } \\
\text { Unidos, se habla inglés, existe estrés por } \\
\text { aculturación, discriminación y se tienen } \\
\text { relaciones interpersonales negativas. } \\
\text { Existe menos aculturación cuando se tiene } \\
\text { mejor trabajo, educación e ingreso } \\
\text { económico, pero existe mayor } \\
\text { aculturación cuando hay baja cohesión } \\
\text { familiar y el migrante sufre de } \\
\text { discriminación. La elevada cohesión } \\
\text { familiar protege contra el trastorno de } \\
\text { ansiedad generalizada(32). }\end{array}$ \\
\hline
\end{tabular}

\begin{abstract}
Investigar el vínculo entre el estrés aculturativo durante sus dos años iniciales en los Estados Unidos y la disminución de la cohesión familiar desde los contextos anteriores a la migración(11).
\end{abstract}

Conocer por qué la aculturación aumenta el consumo de tabaco entre los jóvenes hispanos y por qué esto es especialmente cierto para las adolescentes, además de conocer cómo influyen, los roles de género y la familia en la práctica del consumo de tabaco(33).

$\begin{array}{ll}\text { Adultos latinos } & \text { Estudio de Cohorte retrospectivo, } \\ \text { migrantes que radican } & \text { con } 2 \text { años de seguimiento a 405 } \\ \text { en Miami, Florida(11). } & \text { latinos. Se utilizó la Escala de } \\ & \text { función familiar y el Inventario de } \\ & \begin{array}{l}\text { Estrés Hispano - Versión para } \\ \text { migrantes. }\end{array}\end{array}$

Estudiantes hispanos adolescentes del Sur de California, de 12 a 16 años de edad, principalmente de ascendencia mexicana(33).

\begin{tabular}{lrr}
\hline \multicolumn{2}{l}{ Investigar } & \multicolumn{2}{c}{ asociaciones } \\
entre aculturación y \\
enculturación y valores \\
culturales & hispanos, \\
funcionamiento & familiar \\
(cohesión y & conflicto \\
familiar) y & síntomas \\
depresivos(34). $^{(3)}$ &
\end{tabular}

Estudiantes del $9^{\circ}$ al $11^{\circ}$ grado del Sur de California, quienes se identificaron como hispanos(34).
Estudio longitudinal (3 años) en 7 escuelas secundarias en el área de Los Ángeles con 1.436 adolescentes. Se utilizaron las escalas de aculturación (Versión abreviada de la escala revisada de calificación de aculturación para mexicanoestadounidense) ARMA_II y de cohesión familiar (evaluada por 6 preguntas de FACES II).
Los participantes con mayor nivel educativo, con estatus de documentado y con familia en los Estados Unidos reportaron mayor cohesión familiar antes y después de la migración, y menor estrés por aculturación(11).
Estudio longitudinal en 7 escuelas secundarias en el área de Los Ángeles, con una muestra de 1.922 estudiantes a quienes se les aplicó las escalas de aculturación (Versión abreviada de la escala revisada de calificación de aculturación para mexicanoestadounidense

ARMA_II) y de cohesión familiar (evaluada por 6 preguntas de FACES II.

Estudiar las asociaciones entre el consumo de alcohol y las tendencias de búsqueda de sensaciones, la aculturación y el entorno social entre los jóvenes de origen mexicano(35).

\begin{abstract}
Adolescentes origen mexicano, que provenían de una cohorte poblacional de hogares de origen mexicano iniciada en 2001(35).
\end{abstract}

Estudio longitudinal de 2 años y medio con 1.053 adolescentes mexicanos, a quienes se encuestó inicialmente en sus hogares y posteriormente por teléfono. Se utilizó la Escala de aculturación lingüística y la escala ADFLQ (the adolescent drinking and family life questionnaire) para medir la cohesión familiar.
No se encontró asociación entre la cohesión familiar y el uso de cigarrillo. La aculturación se asoció negativamente con los roles tradicionales de género y positivamente con la disminución de la discriminación. Las mujeres son más aculturadas que los hombres y experimentan pérdida en los roles tradicionales de género que las predispone a mayor conflicto y menor cohesión familiar. El fatalismo se asoció con discriminación más frecuente, mayor aculturación y menor cohesión familiar(33).

La alta cohesión familiar correlaciona positivamente con la identidad hispana, el familismo, el respeto, los roles de género y con bajos síntomas depresivos, además correlaciona negativamente con el fatalismo. La aculturación aumenta el familismo y el respeto y disminuye los roles tradicionales de género ${ }^{(34)}$.

Los participantes que habían consumido alcohol reportaron menor cohesión familiar que sus pares que no lo habían hecho.

El aumento de edad y ser mujer estuvo asociado con el consumo de alcohol, mientras que la aculturación no mostró asociación(35). 


\section{Hallazgos relevantes}

En la mayoría de las investigaciones con migrantes la cohesión familiar aparece como factor que favorece la salud al propiciar la actividad física moderadavigorosa y proteger contra el consumo de alcohol, marihuana y drogas duras. Mientras que los procesos de aculturación se relacionan con mayor presencia de obesidad, tabaquismo, riesgo cardiovascular $\mathrm{y}$ sedentarismo.

Son pocas las investigaciones que han tratado de explicar los efectos que tiene la migración sobre la cohesión familiar y la aculturación y cómo estas variables a su vez influyen en los estilos de vida. Sin embargo, en términos generales los resultados sugieren que el proceso de aculturación que vive el migrante puede tener efectos nocivos para su salud. A su vez, se identifica una posible ruta de acción por las evidencias de que la cohesión familiar puede actuar como mediador para mitigar los efectos de la migración.

\section{Discusión}

Queda claro que el migrante no solo cambia de espacios y de personas con las que convive, sino que también existen procesos internos relacionados con la cohesión familiar y la aculturación que se movilizan en función de la exposición y la aceptación que se tenga hacia los valores, costumbres y tradiciones de la cultura receptora, al igual de las personas con las que conviva y los ambientes a los que se exponga.

Los migrantes traen consigo varias características de su cultura, las cuales, son expresadas a través de diferentes comportamientos ${ }^{(32)}$ como el rendimiento académico(36) y la forma de asumir los roles de género(34). Sin embargo, una vez que se encuentran en el lugar receptor, estas características pueden empezar a modificarse en función de las demandas del nuevo ambiente generando tensiones que pueden impactar a la familia y su cohesión.

La disminución en la cohesión familiar acompañada de la práctica y adopción de las actividades de la cultura receptora, que algunas veces conlleva tensión financiera del migrante(37), acelera el proceso de aculturación. Dicho proceso puede ser más favorable conforme existen niveles de educación más altos y tienen mejor posicionamiento laboral e ingreso económico(32).
Con respecto a la salud, se ha visto que los migrantes recién llegados presentan hábitos más saludables(38), en comparación con los que llevan más tiempo y/o los individuos que son originarios del lugar receptor, esto pudiera estar mediado por una mejor cohesión familiar, sin embargo no hay mucha evidencia al respecto. Lo que se sabe es que mantener estos hábitos saludables no es sencillo porque el migrante va adquiriendo rasgos, ideologías y conductas de la nueva cultura (aculturación), que pueden alterar de forma negativa su estilo de vida y en consecuencia su salud.

Lo que resulta evidente es que la cohesión familiar se asocia con mejores hábitos de actividad física(24), de alimentación( ${ }^{(39)}$ y disminución de la probabilidad de consumir sustancias como alcohol(25), tabaco(23), marihuana y drogas duras(26). Mientras que la aculturación se ha asociado con el tabaquismo(29), especialmente en mujeres(31), el alcoholismo, el aumento de horas frente al televisor(21) y la ganancia de peso corporal(40), ocasionado por el sedentarismo, menor ingesta de frutas y verduras y mayor consumo de azúcar y grasas añadidas(38). Estos hábitos son factores de riesgo para la salud por cuanto desencadenan enfermedades crónicas no trasmisibles, por lo tanto, fortalecer la cohesión familiar del migrante puede traer beneficios para su salud y calidad de vida.

Para favorecer la salud del migrante es necesario que se fortalezca el respeto a las diferencias culturales, es necesario también que se reivindique el papel de la familia como un factor protector que puede potenciar los resultados en salud.

\section{Conclusiones}

La migración es un fenómeno común en el mundo y cada día más frecuente, que trae aparejado un proceso de aculturación: conforme aumenta la exposición a las nuevas prácticas, costumbres, valores y tradiciones va disminuyendo su identidad cultural. Algunas investigaciones ponen en manifiesto que a mayor aculturación por parte del migrante, disminuye la cohesión familiar y esto a su vez, propicia conductas de riesgo para su salud. Por su parte, elevados niveles de cohesión familiar se han relacionado con estilos de vida saludables (alimentación, ejercicio, no consumo de sustancias tóxicas). 


\section{Recomendaciones}

Los hallazgos de las investigaciones revisadas permiten suponer que fomentar la cohesión familiar del migrante puede ser una estrategia para evitar la adquisición de conductas de riesgo para la salud que pueden acompañar el proceso de aculturación. Por otra parte, es importante evaluar la aculturación de forma integral, incluyendo otras dimensiones como costumbres y tradiciones, ya que mucho de lo que se ha investigado se focaliza en el aspecto lingüístico, principalmente enfocado en el uso y aprendizaje del idioma de la cultura receptora.

Por lo anterior, se recomiendan estudios longitudinales que permitan determinar en qué momento del proceso de migración disminuye la cohesión familiar y que otros efectos tiene la migración y la aculturación sobre la salud del inmigrante, además, es necesario incluir algunas otras características como, valores sociales, culturales y familiares, prácticas y actividades que son propias del lugar de origen y valores relacionados con el género y la familia. Por último, es necesario continuar en el desarrollo de escalas para medir interculturalidad, aculturación o hibridación cultural para distintas poblaciones, ya que las que se disponen son antiguas y solamente han sido adaptadas a unas culturas.

\section{Conflicto de intereses}

Ninguno.

\section{Referencias}

1. Ozer S. Theories and Methodologies in Acculturation Psychology: The Emergence of a Scientific Revolution? Psychological Studies. 2013;58(3):339-48.

2. García-Canclini N. La cultura visual en la época del posnacionalismo ¿Quién nos va a contar la identidad? Nueva Sociedad. 1993:180-1.

3. Tirzo Gómez J, Hernández JG. Relaciones interculturales, ¡nterculturalidad y multiculturalismo; teorías, conceptos, actores y referencias. Cuicuilco. 2010;17:11-34.

4. Moebus Retondar A. Hibridismo cultural: ¿clave analítica para la comprensión de la modernización latinoamericana? La perspectiva de Néstor García Canclini. Sociológica (México). 2008;23:33-49.

5. Marsiglia FF, Parsai M, Kulis S. Effects of Familism and Family Cohesion on Problem Behaviors among Adolescents in Mexican Immigrant Families in the Southwest U.S. J Ethn Cult Divers Soc Work. 2009;18(3):203-20.

6. Ferrer R, Palacio J, Hoyos 0, Madariaga C. Proceso de aculturación y adaptación del inmigrante: características individuales y redes sociales. Psicología desde el Caribe. 2014;31:557-76.
7. Chadda RK, Deb KS. Indian family systems, collectivistic society and psychotherapy. Indian J Psychiatry. 2013;55(Suppl 2):S299-309.

8. Campos-Uscanga $Y$, Morales-Ortiz AV, Argüelles-Nava VG, Ramírez-Chang LA, Zavaleta-Abad RA, Rosas-Campos R. Family cohesion and a father's warmth are related to the positive lifestyles of female university students. Kontakt. 2018;20(2):e185-e91.

9. Gallo LC, Penedo FJ, Espinosa de los Monteros K, Arguelles W. Resiliency in the face of disadvantage: do Hispanic cultural characteristics protect health outcomes? J Pers. 2009;77(6):1707-46.

10. Ibanez GE, Dillon F, Sanchez M, M DLR, Li T, Villar ME. Changes in Family Cohesion and Acculturative Stress among Recent Latino Immigrants. J Ethn Cult Divers Soc Work. 2015;24(3):219-34.

11. Dillon FR, De La Rosa M, Ibañez GE. Acculturative Stress and Diminishing Family Cohesion Among Recent Latino Immigrants. Journal of Immigrant and Minority Health. 2013;15(3):484-91.

12. Albert I, Coimbra SB. Family Cultures in The Context of Migration and Ageing. Integrative Psychological and Behavioral Science. 2017;51(2):205-22.

13. Warner LA, Valdez A, Vega WA, de la Rosa M, Turner RJ, Canino G. Hispanic drug abuse in an evolving cultural context: an agenda for research. Drug Alcohol Depend. 2006;84(Suppl1):S8-16.

14. Lopez-Class M, Castro FG, Ramirez AG. Conceptions of acculturation: a review and statement of critical issues. Soc Sci Med. 2011;72(9):1555-62.

15. Nair RL, Roche KM, White RMB. Acculturation Gap Distress among Latino Youth: Prospective Links to Family Processes and Youth Depressive Symptoms, Alcohol Use, and Academic Performance. J Youth Adolesc. 2018;47(1):105-20.

16. Ruiz RJ, Pickler RH, Marti CN, Jallo N. Family cohesion, acculturation, maternal cortisol, and preterm birth in Mexican-American women. Int J Womens Health. 2013;5:243-52.

17. Berry JW, Phinney JS, Sam DL, Vedder P. Immigrant youth in cultural transition: Acculturation, identity, and adaptation across national contexts. Mahwah, NJ: Lawrence Erlbaum Associates Publishers; 2006.

18. Erten EY, van den Berg P, Weissing FJ. Acculturation orientations affect the evolution of a multicultural society. Nat Commun. 2018;9(1):58.

19. Thomson MD, Hoffman-Goetz L. Defining and measuring acculturation: a systematic review of public health studies with Hispanic populations in the United States. Soc Sci Med. 2009;69(7):983-91.

20. Ho J, Birman D. Acculturation gaps in Vietnamese immigrant families: Impact on family relationships. Int J Intercult Relat. 2010;34(1):22-3.

21. Hutton B, Catala-Lopez F, Moher D. [The PRISMA statement extension for systematic reviews incorporating network meta-analysis: PRISMA-NMA]. Med Clin (Barc). 2016;147(6):262-6.

22. Li S, Delva J. Social capital and smoking among Asian American men: an exploratory study. Am J Public Health. 2012;102(Suppl 2):S212-21.

23. Cano MA, Schwartz SJ, Castillo LG, Unger JB, Huang S, Zamboanga BL, et al. Health risk behaviors and depressive symptoms among Hispanic adolescents: Examining acculturation discrepancies and family functioning. J Fam Psychol. 2016;30(2):254-65. 
24. Bigman G, Rajesh V, Koehly LM, Strong LL, Oluyomi AO, Strom SS, et al. Family Cohesion and Moderate-to-Vigorous Physical Activity Among Mexican Origin Adolescents: A Longitudinal Perspective. J Phys Act Health. 2015;12(7):1023-30.

25. DiBello AM, Gonzales R, Young CM, Rodriguez LM, Neighbors C. Blood is thicker than booze: Examining the role of familism and gender in alcohol use and related consequences among Hispanic college students. J Ethn Subst Abuse. 2016;15(3):310-24.

26. Escobedo P, Allem JP, Baezconde-Garbanati L, Unger JB. Cultural values associated with substance use among Hispanic emerging adults in Southern California. Addict Behav. 2018;77:267-71.

27. Evenson KR, Sarmiento OL, Ayala GX. Acculturation and physical activity among North Carolina Latina immigrants. Soc Sci Med. 2004;59(12):2509-22.

28. Isasi CR, Ayala GX, Sotres-Alvarez D, Madanat H, Penedo F, Loria $\mathrm{CM}$, et al. Is acculturation related to obesity in Hispanic/Latino adults? Results from the Hispanic community health study/study of Latinos. J Obes. 2015;2015:186276.

29. Chang A, Kenya S, Ilangovan K, Li H, Koru-Sengul T, Alonzo Y, et al. Is greater acculturation associated with an increased prevalence of cardiovascular risk factors among Latinos in South Florida? Med Care. 2015;53(5):417-22.

30. Kaplan RC, Bangdiwala SI, Barnhart JM, Castaneda SF, Gellman MD, Lee DJ, et al. Smoking among U.S. Hispanic/Latino adults: the Hispanic community health study/study of Latinos. Am J Prev Med. 2014;46(5):496-506.

31. Daviglus ML, Talavera GA, Aviles-Santa ML, Allison M, Cai J, Criqui $\mathrm{MH}$, et al. Prevalence of major cardiovascular risk factors and cardiovascular diseases among Hispanic/Latino individuals of diverse backgrounds in the United States. JAMA. 2012;308(17):1775-84.
32. Ai AL, Weiss SI, Fincham FD. Family factors contribute to general anxiety disorder and suicidal ideation among Latina Americans. Womens Health Issues. 2014;24(3):e345-52.

33. Lorenzo-Blanco EI, Unger JB, Ritt-Olson A, Soto D, BaezcondeGarbanati L. A longitudinal analysis of Hispanic youth acculturation and cigarette smoking: the roles of gender, culture, family, and discrimination. Nicotine Tob Res. 2013;15(5):957-68.

34. Lorenzo-Blanco EI, Unger JB, Baezconde-Garbanati L, RittOlson A, Soto D. Acculturation, enculturation, and symptoms of depression in Hispanic youth: the roles of gender, Hispanic cultural values, and family functioning. J Youth Adolesc. 2012;41(10):1350-65.

35. Wilkinson AV, Shete S, Spitz MR, Swann AC. Sensation seeking, risk behaviors, and alcohol consumption among Mexican origin youth. J Adolesc Health. 2011;48(1):65-72.

36. Guo M, Steinberg NS, Dong X, Tiwari A. A cross-sectional study of coping resources and mental health of Chinese older adults in the United States. Aging Ment Health. 2018;22(11):1448-55. 10.1080/13607863.2017.1364345.

37. East PL, Chien NC. Family dynamics across pregnant Latina adolescents' transition to parenthood. J Fam Psychol. 2010;24(6):709-20.

38. Perez-Escamilla R. Acculturation, nutrition, and health disparities in Latinos. Am J Clin Nutr. 2011;93(5):1163S-7S.

39. Abraído-Lanza AF, Echeverría SE, Flórez KR. Latino Immigrants, Acculturation, and Health: Promising New Directions in Research. Annual review of public health. 2016;37:219-36.

40. Delavari M, Sonderlund AL, Swinburn B, Mellor D, Renzaho A. Acculturation and obesity among migrant populations in high income countries--a systematic review. BMC Public Health. 2013;13:458. 